\title{
Retraction Note to: The ecological evaluation of marine water resources based on image super-resolution and the effectiveness of English distance teaching
}

\author{
Xiaochun Lu ${ }^{1}$
}

Published online: 4 November 2021

(c) Saudi Society for Geosciences 2021

Retraction Note to: Arabian Journal of Geosciences (2021) 14: 1804 https://doi.org/10.1007/s12517-021-08177-x

The Editor-in-Chief and the Publisher have retracted this article because the content of this article is nonsensical. The peer review process was not carried out in accordance with the Publisher's peer review policy. The author has not responded to correspondence regarding this retraction.

The original article can be found online at https://doi.org/10.1007/ s12517-021-08177-x.

Xiaochun $\mathrm{Lu}$

xiaochun9843@163.com

1 School of Foreign Languages, Hubei Polytechnic University, Huangshi 435000, Hubei, China 